\title{
Redescription of the female of Gnathia africana (Crustacea: Isopoda: Gnathiidae) from southern Africa
}

\author{
Nico J. Smit ${ }^{1,2}$, Jo G. Van As ${ }^{1}$ and Linda Basson ${ }^{1}$ \\ ${ }^{1}$ Department of Zoology and Entomology, University of the Free State, P.O. Box 339, Bloemfontein, 9300, South Africa; \\ ${ }^{2}$ Present address: School of Life Sciences, Kingston University, Penrhyn Road, Kingston upon Thames, Surrey, KT1 2EE, UK
}

Key words: Gnathiidae, Gnathia africana, female, redescription, taxonomy, morphology

\begin{abstract}
A redescription of the female of the temporary fish parasite, Gnathia africana Barnard, 1914 is provided from specimens reared from final-stage G. africana praniza larvae collected from their intertidal fish hosts along the south coast of southern Africa. It differs from other known gnathiid females in the shape of the frontal border and the number and basic form of pylopod articles. This redescription aims to establish a format for future descriptions and redescriptions of gnathiid females.
\end{abstract}

Barnard (1914a) was unable to collect females to include in his original description of the temporary fish parasite, Gnathia africana Barnard, 1914, but was able to find them at a later stage and briefly described them in Barnard (1914b). As in the case of the males and larvae, Barnard's (1914b) description did not provide detailed information or illustrations. This problem is evident in the fact that the illustration of a G. africana female by Kensley (1978), in his book on isopods from South Africa, is actually that of a larva. Smit et al. (1999) were also unable to collect females and therefore provided only a redescription of the male and praniza larva of G. africana.

Since the taxonomy of gnathiids is based solely on the morphology of the free-living adult male (Cohen and Poore 1994), most authors either ignored females in their species descriptions or described their basic morphology in only a few sentences. The aim of this redescription is to provide a detailed record of the females of G. africana. This should make it possible to identify females in the absence of the males, and establish a format that can be used for future descriptions of female gnathiids of new species, as well as for redescriptions of females of known species.

\section{MATERIALS AND METHODS}

Adult stages were obtained by rearing the final-stage $G$. africana praniza larvae collected from their intertidal fish hosts at Jeffreys Bay in January 1999 [see Davies and Smit (2001) for infestation statistics]. These final-stage larvae were kept in $50 \mathrm{ml}$ plastic screw-top containers of seawater at temperatures between $20-25^{\circ} \mathrm{C}$ until they moulted into adult males and females. The whole life cycle was completed under laboratory conditions. Males and females developed from the same population of final-stage larvae. These G. africana males mated with the females, which then produced offspring. This confirms the species identification of the females beyond doubt. A number of adult females were fixed in $70 \%$ ethanol and prepared for light and scanning electron microscopy, following the same methods described elsewhere (see Smit et al. 1999). Remaining adults and larvae were used in life-cycle experiments.

In order to establish a uniform format for the description, 29 of the 72 taxonomically important characteristics defined for male gnathiids by Cohen and Poore (1994) were applied in the present study, since these were applicable to females. These characteristics included those of the eyes, antennae, pereon, pleon, pleotelson, uropods, pereopods and pleopods. Due to the large morphological differences between gnathiid males and females the remaining 43 characteristics dealing with specific male features, such as the enlarged cephalosome, frontal border, mandibles, pylopods and maxillipedes could not be used. In addition to the 29 shared characteristics, those unique to females, that is the morphology of the cephalosome, pylopods, maxillipedes and oostegites, were identified and included in the description.

\section{RESULTS}

Gnathia africana Barnard, 1914

Adult female

Figs. 1-13

Description: Total length of material examined: 3.2$4.3 \mathrm{~mm}(3.74 \pm 0.3 \mathrm{~mm}, \mathrm{n}=11)$.

Cephalosome. Broadened, short. Rectangular, 1.5 times as wide as long, two to four pairs of short simple setae on dorsal cephalosome, median area of posterior margin slightly concave (Figs. 1, 2, 10). Well-developed oval-shaped, bulbous, compound eyes on lateral margin of cephalosome, length of eye two thirds of cephalosome (Fig. 11). No paraocular ornamentation, only three to five short simple setae.

Frontal border. Broadly rounded, produced, with four short simple setae on mid dorsal area (Fig. 2).

Antennae. Antenna 2 longer than antenna 1. Antenna 1 with three peduncle articles increasing in length distally with third article as long as first and second 

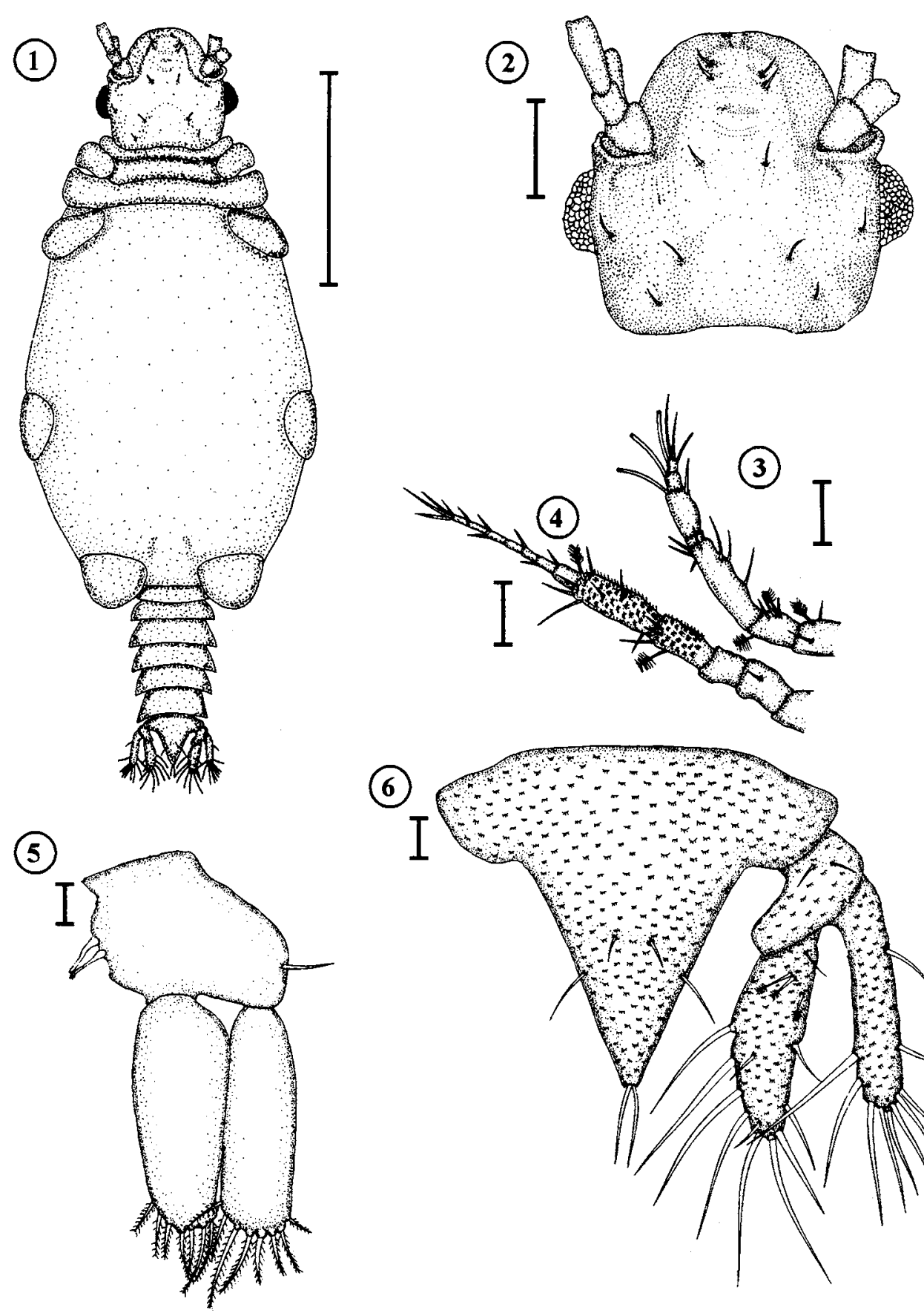

(6)
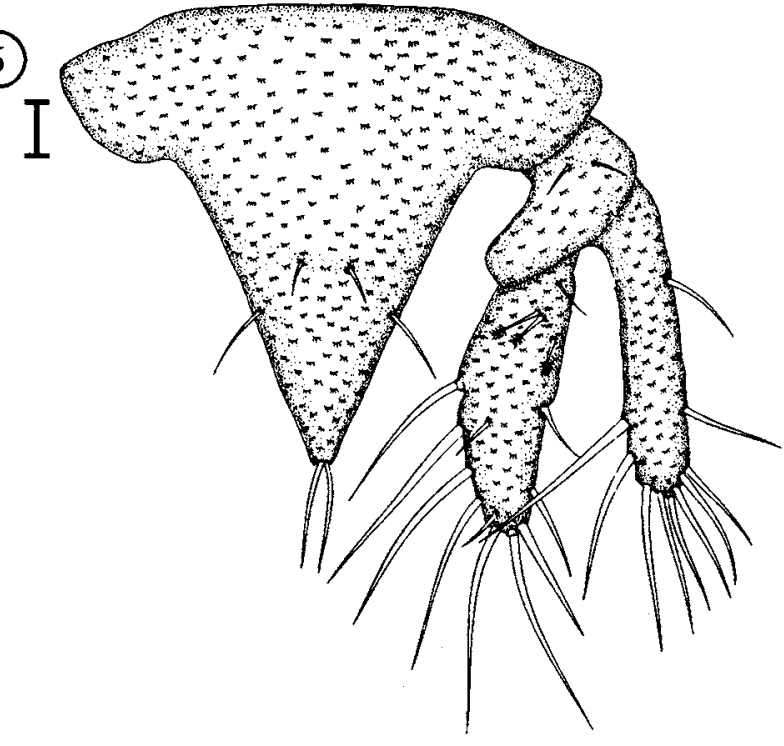

Figs. 1-6. Microscope projection drawings of a female Gnathia africana Barnard, 1914. Fig. 1. Full length dorsal view. Fig. 2. Dorsal cephalosome. Fig. 3. First antenna. Fig. 4. Second antenna. Fig. 5. Right pleopod 1. Fig. 6. Pleotelson and uropods. Scale bars: Fig. $1=1 \mathrm{~mm}$; Fig. $2=500 \mu \mathrm{m}$; Figs. $3-6=100 \mu \mathrm{m}$.

articles combined. Single feather-like seta and few short simple setae on distal end of articles 1 and 2, two feather-like setae and two to five short simple setae on article 2. Five to nine short simple setae on article 3. Flagellum with four articles, article 2 largest, articles 2 and 3 with one aesthetasc seta each, article 4 terminating in one aesthetasc and three simple setae (Fig. 3). Antenna 2 with five peduncle articles, article 5 largest, a single short simple seta on article 2 and three to seven short simple setae and a single feather-like seta on distal ends of articles 4 and 5 respectively. Articles 4 and 5 covered with pectinate scales. Flagellum with seven articles, article 1 largest, article 7 terminating in three to four simple setae (Fig. 4).

Mandible. Absent.

Maxilla. Both maxillae 1 and 2 absent. 

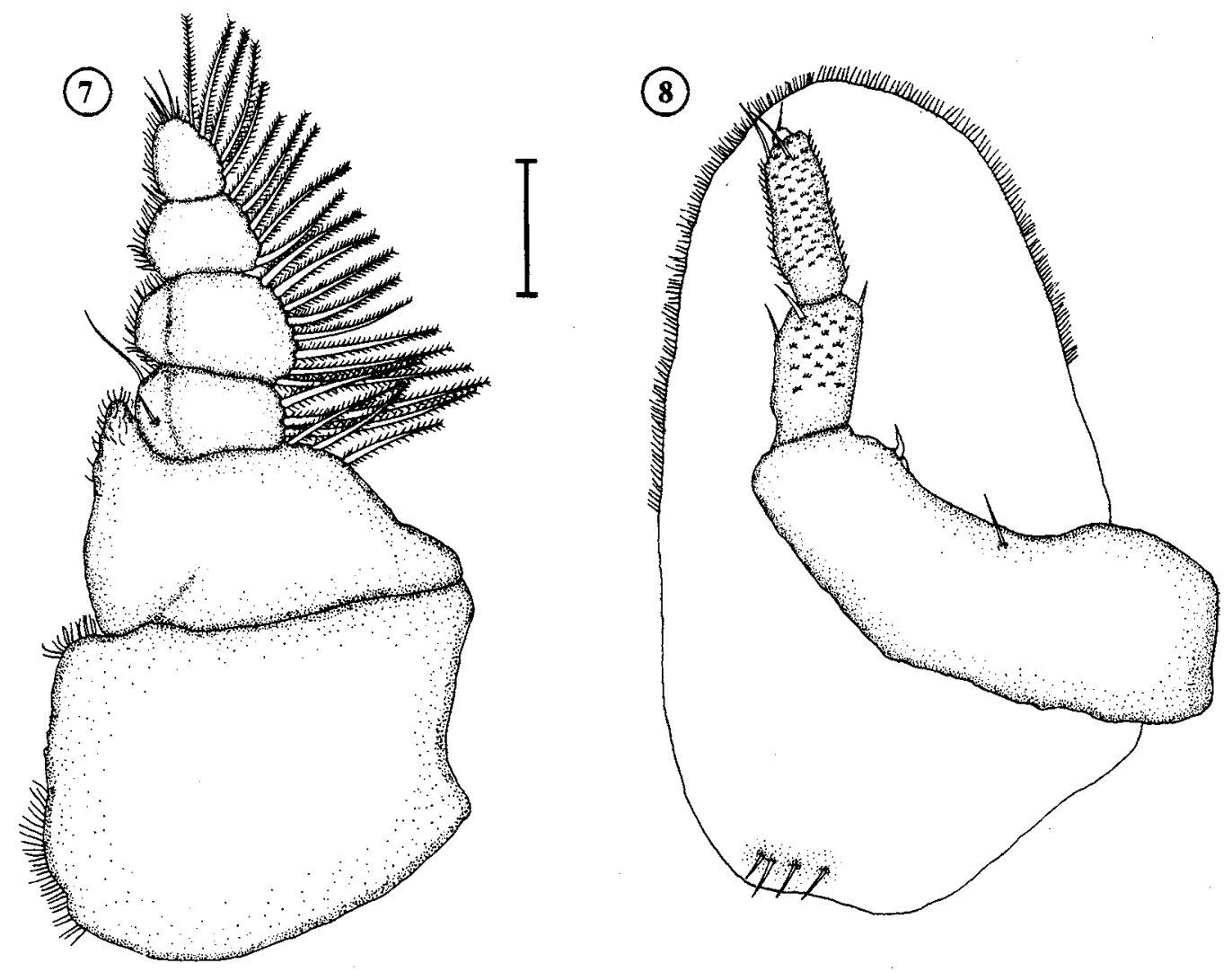

Figs. 7-8. Microscope projection drawings of the mouthparts of a female Gnathia africana Barnard, 1914. Fig. 7. Maxilliped. Fig. 8. Pylopod. Scale bar: $100 \mu \mathrm{m}$.

Maxilliped. Consists of coxa with attached oostegite, basis and four-articled palp (Fig. 7). Endite short, setose, not reaching article 2 of palp. Lateral margins of basis fringed with three long plumose setae. Palp bearing plumose setae on lateral margins in order of $3-8-5-5$, article 1 of palp with single short simple and a single long simple seta on the mesial border (Fig. 7). Distal article of palp with four to five short simple setae. Mesial borders of palp, basis and coxa with oostegite densely setose.

Pylopod. Four articles; articles 1 and 2 fused. Article 1 broad, robust, curved anteriorly, with a single simple seta mid-dorsally and a short curved robust seta dorsolaterally (Figs. 8, 12). Article 2 with two to four simple setae distally. Article 3 with two to four simple setae distally. Article 4 small with one to two simple setae. Surface of articles 2 and 3 covered with pectinate scales. Lateral borders of article 2 with short hair-like simple setae. Oval-shaped oostegite, twice as broad than long, covers maxillipedes ventrally, not surpassing frontal border (Fig. 12). Three to five short simple setae on posterior surface of oostegite, lateral and anterior borders with short hair-like simple setae.

Pereon. Swollen, round, sutures between pereonites 5-7. One and a half times as long as wide, wider than cephalosome (Fig. 1), short simple setae on lateral areas. Pereonite 7 dorsally visible, small with rounded posterior margin, overlapping first pleonite. Ventral area of pereonite 6 with prominent slit (Fig. 13), function of slit unknown.

Pleon. Pleon and pleotelson less than a quarter of total length (Fig. 1). Five subequal pleonites dorsally visible, epimera not distinct, short hair-like setae and short setose setae randomly distributed on pleonites.

Pleotelson. Triangular, base as wide as or wider than length, lateral margins straight, dorsal surface with two pairs of simple setae and pectinate scales, distal apex terminating in pair of long simple setae (Fig. 6).

Pereopods. Pereopod 2 basis elongated, oval-shaped, with two to three feather-like setae and short simple setae anteriorly, two to five posterior simple setae (Fig. 9). Ischium two-thirds length of basis, three to five anterior short simple setae, three short simple setae posteriorly. Merus half the length of ischium with anterior bulbous protrusion, three simple setae on bulbous protrusion, posterior margin with two to three tooth-shaped tubercles as well as two short and a single long simple seta. Carpus of almost same size and shape as merus, but without anterior bulbous protrusion, posterior margin with eight to ten tooth-shaped tubercles, simple setae and a single feather-like seta. Propodus about twice the length of carpus, tooth-shaped 

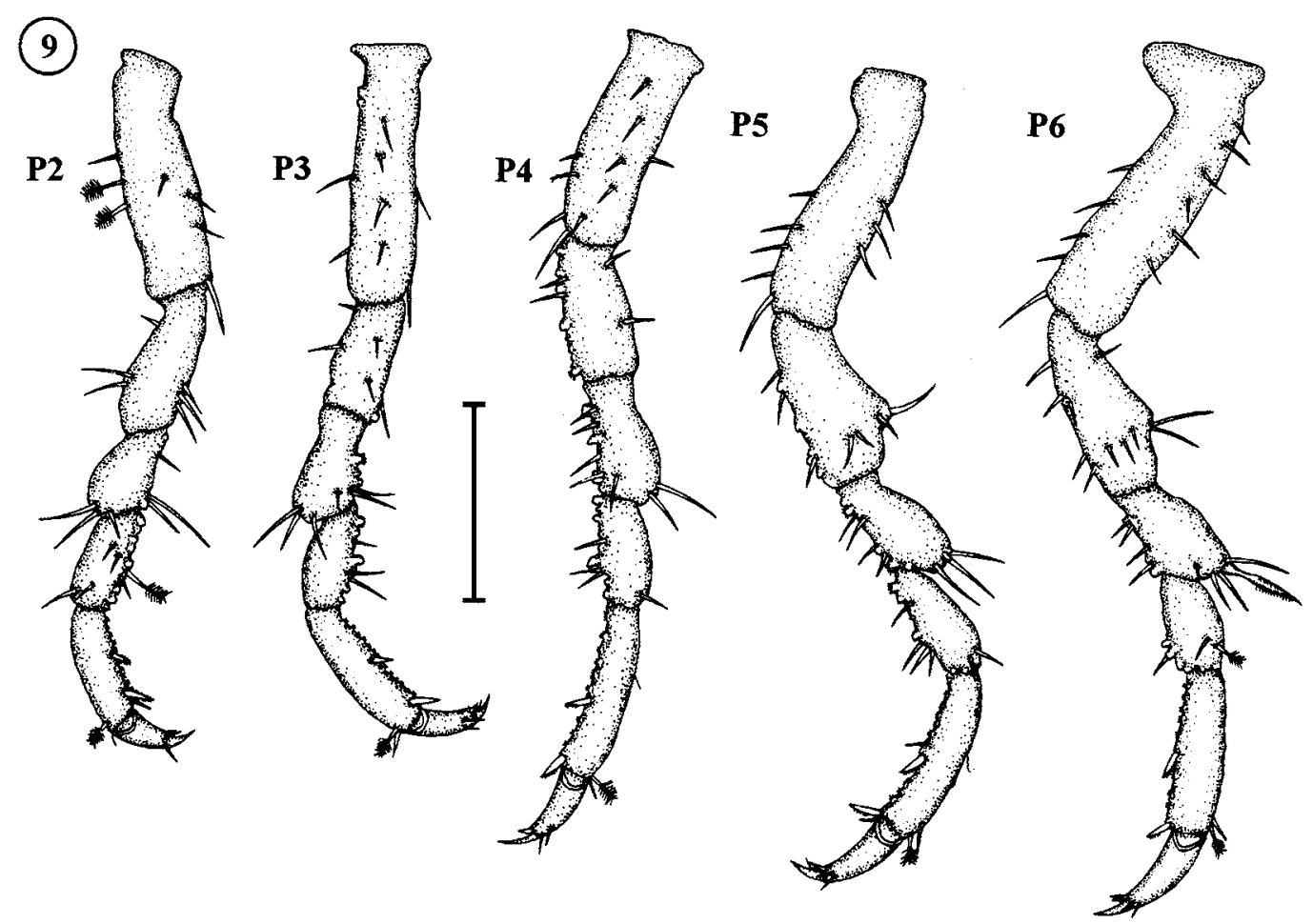

Fig. 9. Microscope projection drawings of pereopods 2 to 6 (P2-P6) of a female Gnathia africana Barnard, 1914. Scale bar: $200 \mu \mathrm{m}$.

tubercles on posterior margin, two robust denticulated setae situated on middle and distal part of posterior margin respectively, single simple seta and one featherlike seta anterio-distally. Dactylus half the length of propodus, terminates in sharp posterior pointing unguis, robust seta on posterior side proximal to unguis, few simple setae on dorsal and ventral sides of robust seta. Pereopods 3 to 6 similar to pereopod 2 in basic form, differ in setation, shape and number of tubercles (Fig. 9). Pereopod 6 with single strong denticulated compound seta on posterior bulbous protrusion of merus. Dorsal surface of ischium, merus, carpus and propodus of all pereopods covered with pectinate scales (not shown in illustrations). Thin plate-like oostegites attached to coxae of pereopods 4 to 6 , brood pouch enclosed by overlapping oostegites.

Pleopod. Pleopod 1 endopod slightly shorter and wider than exopod. Both fringed distally with seven to eight short plumose setae (Fig. 5). No coupling hooks visible. Sympodite with retinacula, single simple seta on lateral margin. Pleopods 2 to 5 similar to pleopod 1.

Uropod. Rami extending beyond apex of pleotelson, endopod longer and wider than exopod, both with long simple setae, pectinate scales on dorsal area of uropods (Fig. 6). Endopod with three feather-like setae and three simple setae on dorsal surface. A pair of short simple setae on uropodal basis.

For the deposition of the type and other material of $G$. africana see Smit et al. (1999).
Material examined in present study: In the collection of Aquatic Parasitology, Department of Zoology and Entomology, University of the Free State, Bloemfontein (11 females, Reference No. 99/02/02-01).

\section{DISCUSSION}

The lack of detailed descriptions of females of other gnathiid species makes it difficult to provide a comprehensive comparison of this species with those already described. For example, no detailed description exists for any of the females of the gnathiids described from Australia, an area with species that seem closely related to those reported from South Africa (Smit and Van As 2000).

According to Monod (1926) the flagellum of antenna 2 of Paragnathia formica (Hesse, 1864) females from France, consists of eight articles and the pylopod of six articles. These characteristics, as well as the shape of the frontal border, clearly separate it from G. africana (antenna 2 flagellum with seven articles and pylopod with four articles). According to Brandt and Wägele (1991) the flagellum of antenna 2 of the females of a species in another genus, Euneognathia gigas (Beddard, 1886), also consists of eight articles, as in the case of $P$. formica, but the pylopod has only four. The pleotelson of the E. gigas female is almost twice as long as wide in comparison to those of $G$. africana females that are almost as broad as long. Gnathia africana females can 

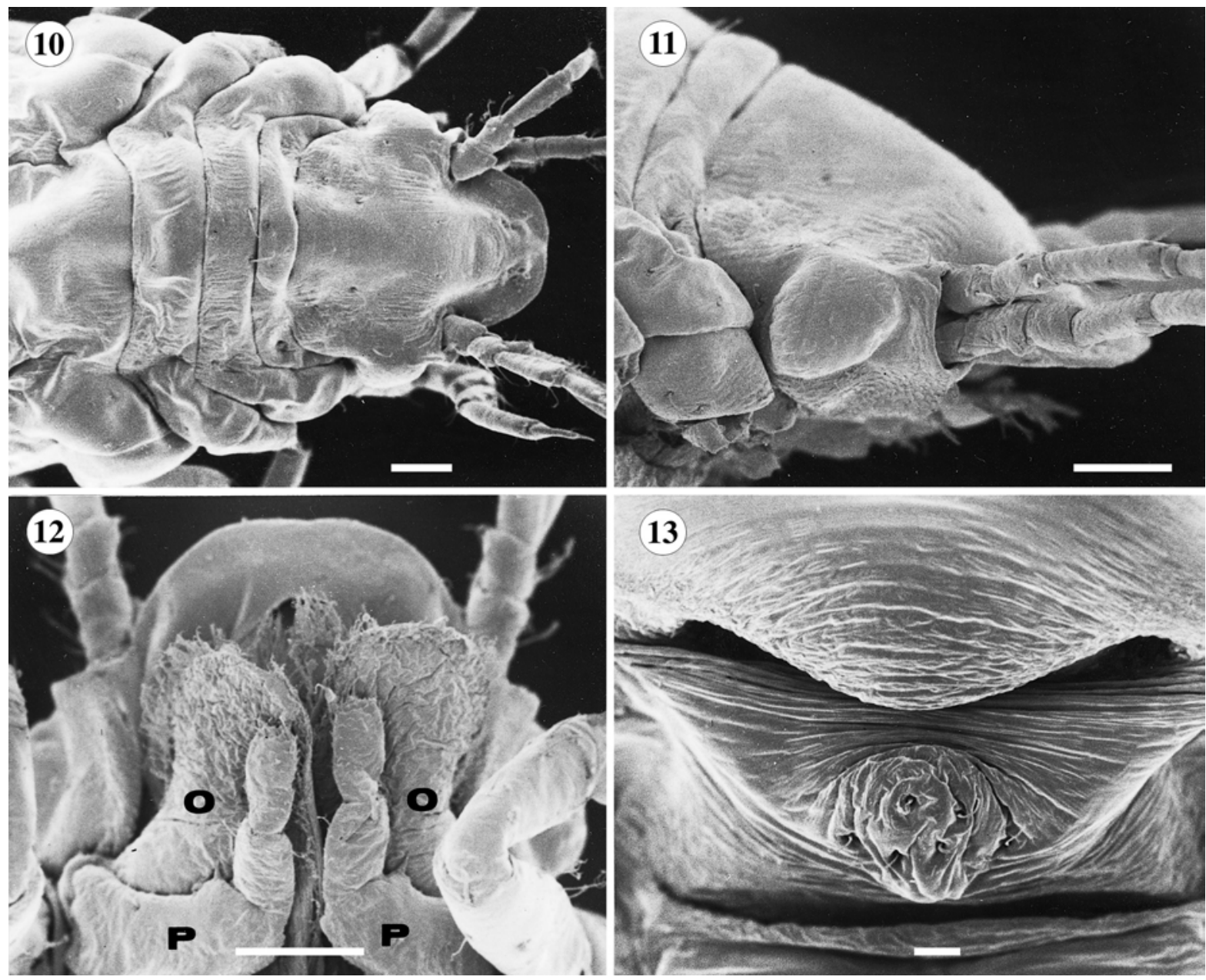

Figs. 10-13. Scanning electron micrographs of a female Gnathia africana Barnard, 1914. Fig. 10. Dorsal view of cephalosome and pereonites 1-3. Fig. 11. Lateral view of cephalosome and right eye. Fig. 12. Ventral view of pylopods (P) and pylopodal oostegites (O). Fig. 13. Ventral view of prominent slit on pereonite 6. Scale bars: Figs. 10-12=100 $\mu \mathrm{m}$; Fig. $13=10 \mu \mathrm{m}$.

also be distinguished from those of Caecognathia calva (Vanhöffen, 1914) by the shape of the frontal border, the number and basic form of the pylopod articles (two articles with first one broadened in C. calva) and the presence of plumose uropodal setae (see Wägele 1987).

The males of Gnathia firingae Müller, 1991 are very similar to G. africana males (Müller 1991, Smit et al. 1999). The females also show remarkable similarities, specifically in the presence of a produced rounded frontal border and the shape of the pleotelson. Unfortunately the description of $G$. firingae females by Müller (1991) is not sufficiently detailed and therefore a comprehensive comparison is impossible.

Acknowledgements. The authors thank Prof. Angela Davies Russell, Kingston University, UK, for reading the draft copy. This study was funded by the marine resource program of the National Research Foundation (NRF) of South Africa.

\section{REFERENCES}

BARNARD K.H. 1914a: Contributions to the crustacean fauna of South Africa. 1. Additions to the marine Isopoda. Ann. S. Afr. Mus. 10: 197-230.

BARNARD K.H. 1914b: Contributions to the crustacean fauna of South Africa. 3. Additions to the marine Isopoda, with notes on some previously incompletely known species. Ann. S. Afr. Mus. 10: 325a-358a, 359-442.
BRANDT A., WÄGELE W. 1991: Parasitic Isopoda of the family Gnathiidae from the Atlantic sector of the Southern Ocean. Redescriptions and remarks on the synonymy (Crustacea: Isopoda). Senckenb. Marit. 21: 233-261.

COHEN B.F., POORE G.C.B. 1994: Phylogeny and biogeography of the Gnathiidae (Crustacea: Isopoda) with descriptions of new genera and species, most from southeastern Australia. Mem. Mus. Victoria 54: 271-397. 
DAVIES A.J., SMIT N.J. 2001: Studies on the life cycle of Haemogregarina bigemina (Adeleina: Haemogregarinidae) in South African hosts. Folia Parasitol. 48: 169177.

KENSLEY B. 1978: Guide to the Marine Isopods of Southern Africa. The Rustica Press, Wynberg, Cape, 173 pp.

MONOD T. 1926: Les Gnathiidae. Essai monographique (Morphologie, Biologie, Systématique). Mem. Soc. Sci. Nat. Maroc 13: 1-668.

MÜLLER H.G. 1991: Isopoda from coral reefs of Réunion Island: Cirolanidae and Gnathiidae (Crustacea). Cah. Biol. Mar. 32: 371-386.

Received 23 February 2001
SMIT N.J., VAN AS J.G. 2000: A new species, Gnathia nkulu sp. n. (Crustacea: Isopoda: Gnathiidae) from southern Africa. Folia Parasitol. 47: 235-240.

SMIT N.J., VAN AS J.G., BASSON L. 1999: A redescription of the adult male and praniza of Gnathia africana Barnard, 1914 (Crustacea, Isopoda, Gnathiidae) from southern Africa. Folia Parasitol. 46: 229-240.

WÄGELE J.W. 1987: Description of the postembryonal stages of the Antarctic fish parasite Gnathia calva Vanhöffen (Crustacea: Isopoda) and synonymy with Heterognathia Amar \& Roman. Polar Biol. 7: 77-92.

Accepted 28 May 2001 